\title{
Antoine Maubec, Principes physiques de la raison et des passions des hommes
}

\section{Simón Gallegos Gabilondo}

\section{(2) OpenEdition}

1 Journals

\section{Edizione digitale}

URL: http://journals.openedition.org/studifrancesi/3734

DOI: 10.4000/studifrancesi.3734

ISSN: 2421-5856

\section{Editore}

Rosenberg \& Sellier

\section{Edizione cartacea}

Data di pubblicazione: 1 décembre 2012

Paginazione: 565-566

ISSN: 0039-2944

\section{Notizia bibliografica digitale}

Simón Gallegos Gabilondo, «Antoine Maubec, Principes physiques de la raison et des passions des hommes», Studi Francesi [Online], 168 (LVI | III) | 2012, online dal 30 novembre 2015, consultato il 05 mars 2021. URL: http://journals.openedition.org/studifrancesi/3734 ; DOI: https://doi.org/10.4000/ studifrancesi.3734

Questo documento è stato generato automaticamente il 5 mars 2021.

\section{(c)}

Studi Francesi è distribuita con Licenza Creative Commons Attribuzione - Non commerciale - Non opere derivate 4.0 Internazionale. 


\title{
Antoine Maubec, Principes physiques de la raison et des passions des hommes
}

\author{
Simón Gallegos Gabilondo
}

\section{NOTIZIA}

ANTOINE MAUBEC, Principes physiques de la raison et des passions des hommes. Texte établi, présenté et commenté par Paolo Quintili, Paris, Honoré Champion, 2011, pp. 224.

1 Antoine Maubec è un autore la cui opera riguarda tanto la storia della medicina quanto la storia delle idee, distinzione piuttosto problematica particolarmente nei Principes, che vengono presentati in quest'eccellente edizione critica curata da Paolo Quintili. L'opera del medico francese, apparsa nel 1709, si trova all'incrocio di una serie di questioni: la facoltà di medicina di Montpellier, dove si formò, era un ambiente culturale dove prevalevano la curiosità scientifica e un orientamento non dogmatico, in opposizione a quella di Parigi, dove il clima era più conservatore. Quest'ultima università era lontana dallo spirito della nuova medicina meccanicistica e sperimentale, come dimostra il rifiuto della teoria della circolazione del sangue, accettata a Montpellier. Il libro di Maubec s'inserisce in tale contesto storico di passaggio tra due secoli, dove il rifiuto della metafisica delle idee innate è una condizione necessaria affinché le scoperte realizzate dalle scienze biologiche, sulla base dell'osservazione e dell'esperienza, trovino un atteggiamento favorevole.

2 Le conseguenze pratiche e teoriche fanno tutt'uno in tale passaggio da un modello scientifico ad un altro, i cui riferimenti storici sono ben illustrati dall'apparato di note e dall'ampia introduzione che apre il presente volume. Si tratta di un'opera di grande interesse per seguire gli sviluppi della crisi che trova una risposta nel pensiero illuministico, il quale evidentemente non è soltanto quello dei philosophes ma anche quello degli uomini di scienza che avanzarono una critica altrettanto rilevante al cartesianesimo. Si delinea una concezione in base alla quale tra intelletto e organismo, tra l'uomo fisico e l'uomo morale non vi è rottura ma continuità, e dove le funzioni 
psichiche vengono considerate materialisticamente, così come tutte le altre facoltà umane. Tra la fine del XVII e l'inizio del xvIII secolo, al centro della disputa filosofica e scientifica tra le facoltà di medicina di Montpellier e Parigi, le passioni e la ragione umane vengono così ricondotte a dei principi fisici, tra i quali vi è sempre meno posto per il cogito cartesiano, ridotto a una funzione fisiologica. Questo passaggio cruciale, che porterà ad una maggior presenza della nozione materiale d'esprit a scapito di quella, più metafisica, di anima, è incarnato esemplarmente nelle pagine dei Principes. 